\title{
Burned Out Or Just Frustrated? Reasons Why Physical Education Teachers Leave Their Profession
}

Authors' contribution:

A) conception and design of the study

B) acquisition of data

C) analysis and interpretation of data

D) manuscript preparation

E) obtaining funding

\author{
Ryszard Cieśliński ${ }^{1}$ A-E, Ernest Szum ${ }^{2 C, D}$ \\ ${ }^{I}$ Faculty of Physical Education and Sport, Biała Podlaska \\ ${ }^{2}$ University of Physical Education, Warsaw
}

This work focuses on the reasons why physical education (PE) teachers leave their profession. The study included 80 individuals who decided to leave a teaching profession in 2013. A diagnostic poll method with the use of the QWL (Quality of Work Life) index was employed in the study. It was observed that there are usually a number of reasons why they give up their job, the most important being financial reasons. Their decision is influenced by the accumulation of professional and personal problems as well as their inability to solve them. The findings showed that teachers' departure from the profession is generally associated with the issue of burnout; however, financial reasons are most frequently ones that directly affect this decision.

KEYWORDS education, pedagogics, physical education teachers, life quality, working conditions, leaving a profession

\section{Introduction}

In recent years, there have been a lot of alarming publications regarding the decreasing status of the teaching profession and the deteriorating working conditions of teachers. To a large degree this problem particularly concerns physical education (PE) teachers, who experience difficulties connected with both mental and physical effort. As a consequence, more and more individuals give up their teaching jobs. It is, in large measure, noticeable among experienced teachers, approximately half of who seek employment outside the field of physical education (Tucholska, 2009; Whipp et al., 2007; Louis \& Smith, 1991). Obviously, the jobs they have resigned from are quickly taken by newly recruited employees. The problem, though, is that they lack the invaluable and necessary experience. Even highly skilled individuals with no prior teaching history will not be able to replace teachers with long-term experience acquired specifically in this profession. Age and working experience are closely related to the level of professional development, extending knowledge and improving pedagogical skills as well as obtaining further qualifications and acquiring indispensable attributes. Age also influences teachers' approach to their profession.

The aim of this work was to get to know and analyze the direct causes and accompanying reasons that result in experienced PE teachers leaving their profession. 


\section{Material and methods}

The research was conducted on 80 former PE teachers in January and February 2014. The subjects consisted of young teachers aged under 35 (59\%), 36-40-year-olds (27\%), and teachers aged over 40 years $(14 \%)$. The ratio of men to women was $63 \%$ to $37 \%$.

Age was a significant variable, as when it came to leaving their profession, it mattered whether teachers who assessed their professional and social situation were novices "working their way up" or experienced teachers with stable lives.

A diagnostic poll method with the use of an interview was employed in the study (Babbie 2001). A randomly selected sample of former teachers who had worked in different types of schools (primary, lower-, and upper-secondary schools) in the whole of Poland was surveyed.

The QWL (Quality of Work Life) index served as the methodological basis for the research. The QWL index is based on the psychological and social perception of work environment. It is also connected with the level of emotional tension of an individual that results from the specificity of everyday social interactions in a given institution (Louis \& Smith, 1990).

Karen S. Louis and BetsAnn Smith created a theoretical framework for the research method with the use of the QWL index. For the needs of this type of research they selected seven basic criteria necessary when examining the quality of work life. The criteria constitute the QWL index. They include respect from relevant adults, participation in decision-making, frequent and stimulating professional interactions, a high sense of efficacy, the use of skills and knowledge, resources to carry out the job, and goal congruence. On the basis of these criteria it is possible to define the main reasons why PE teachers leave their profession (Louis \& Smith, 1990).

The above-mentioned authors also selected factors used to define QWL criteria. These factors may influence the quality of the work life in teachers. They are made up of components that can be divided into three groups. The first group includes changes in the social and cultural sphere, where the following points may be noted: planning professional development, teacher role-playing, problems of beginner teachers, comparing, and evaluating as well as mechanisms that tighten social bonds. The second group includes changes in the political and administrative sphere, where participation in administering school policy and devolution are significant. The third group is formed by the multiplicity of organizational and technical rules that regulate such issues as the restructuring of teaching conditions with the involvement of students and their parents (Louis \& Smith, 1990).

\section{Results}

According to PE teachers, their psychophysical state, professional self-evaluation, and disposition are most negatively influenced by bad working conditions, subjectively perceived low salary, and mismanagement of education as well as the necessity to work with bigger and bigger groups of students, more and more of whom are socially maladjusted and pose didactic and/or educational challenges. These factors, whether objective or subjective, contribute considerably to the occurrence of burnout syndrome. It develops relatively quickly and is quite common in this professional group. This phenomenon is usually accompanied by teachers' personal problems, which may be a decisive factor as far as leaving this profession is concerned. Such remarks as "accumulating organizational and educational problems", "being helpless against many serious difficulties", and "inability to overcome bureaucratic obstacles", often illustrated the aforementioned problems.

As expected, most frequently teachers pointed to low salary and unsatisfactory financial status as the most significant causes of their professional frustration. In the end, it turned out that they were the main, although not always the direct, reasons for leaving the profession, regardless of how many causes there were in general and how complex they were. Former PE teachers often chose low salary as one of the reasons that eventually brought about their departure from their profession. In this context, the following replies 
prevailed: "I did not have enough money to meet the needs of my family", "my salary was too low to maintain a sufficient standard of living", "I often lacked financial resources", "I did not have enough money to provide for my spouse and children," and "in other places I can earn more than at school".

The research revealed that young age and little working experience are characteristic features of PE teachers leaving their profession. They often make such a decision after working at school for a very short period of time, even for just one year. This stems from the fact that at this stage of their life, young teachers focus on starting a family, which they have to provide for, while at the beginning of a teaching career remuneration is relatively low. Financial reasons are also significant for more experienced teachers who left their profession, although in their case, this is not a decisive factor. Young teachers giving up their jobs, change their profession entirely, and retrain or take up trainer or instructor jobs in private companies which deal with physical culture, e.g., fitness clubs, spas, biological regeneration centers, bodybuilding gyms, swimming pools, etc. Not only are they, as mentioned in the surveys, better paid jobs, but also much less bureaucratic, providing a sense of independence in substantive matters and giving them a chance to be creative.

The results of the interviews showed that non-financial reasons why PE teachers left their profession included being overworked, the lack of mobility in their professional career, physical isolation and few interpersonal contacts with other teachers, low position in an informal teacher's hierarchy, little influence on general matters regarding the school, their routine, and professional burnout. The subjects also mentioned too many responsibilities and no possibilities to work individually with talented students. As a result, both groups were frustrated, as neither the former nor the latter could make use of their potential. All this was connected with PE teachers' low status and the fact that school directors and other teachers, despite their expectations concerning sports achievements, took little notice of PE teachers' suggestions concerning improvements in school functioning that would help attain sports success. PE teachers often complained about the lack of understanding and support from their colleagues and claimed that this resulted from their spatial isolation at school and social distance in interpersonal relations.

In addition, PE teachers complained about overloads regarding the subject curriculum. They claimed that, as a result, they had to cover some material superficially and in a hurry. They also reported that school directors as well as other teachers and even students' parents had too high expectations concerning interschool and regional competitions (individual and team sports). Limited contact with other teachers was another big problem. This resulted from the specificity of PE classes, as they are usually conducted outdoors (football pitches, athletic tracks, swimming pools, etc.) or in architecturally isolated sports halls. In their opinion, the type of work they do and hard conditions make them "get stuck in a rut", which often leads to burnout and eventually forces them to leave the profession. The support from older and more experienced teachers could be a solution but establishing closer interpersonal relations would be difficult due to the lack of more frequent direct interactions. This is brought about by the fact that PE teachers conduct their classes outside or in an isolated part of the school buildings and, as a result, they cannot visit the staff room or meet other teachers in the corridors during breaks very often.

The data gathered during the interviews indicated that PE teachers also encountered difficulties resulting from the improper attitude of teachers of other subjects, school directors, parents, and students towards PE teachers and the classes they conduct. PE teachers' approach to themselves and their subject was also an issue. Its low status and little interest in physical culture caused PE teachers to feel inferior and resulted in their negative self-evaluation and loss of initiative as well as contributing to the deterioration of working conditions. They often heard opinions expressed by their colleagues and people in general that PE was not education and that their work consisted of rolling, running, and ball chasing, and that the subject itself was not important in educating children and youth.

Professionally dissatisfied PE teachers often felt that their work got out of control both in terms of goals and methods, which led to a lack of autonomy and undermined authority. Furthermore, they claimed that they were affected by manipulation on the part of school directors and by bureaucratic responsibilities 
they did not receive extra remuneration for. They often felt powerless and claimed that their participation in making significant decisions was limited and they had no real influence on the course of work with children and youth.

The application of the QWL index made it possible to determine PE teachers' self-perception and perception of their work environment and work effects. The QWL index criteria helped to note that the lack of PE teachers' professional satisfaction translated directly into the inferior quality of their professional and personal lives. The QWL index also allowed for precise identification and categorization of the main reasons why PE teachers left their profession.

\section{Discussion}

Being a teacher in general and a PE teacher in particular requires serving (often simultaneously) several social and professional roles, e.g., of a public servant, a group leader, an arbiter, an organizer, an animator, moral authority, and, obviously, a teacher and educator. Each of the roles has its own specific demands, the most significant being social interactions, emotional involvement in interpersonal contacts, possession and constant development of adequate competences, dealing with difficult situations, and solving problems effectively. Proper fulfillment of social roles increases the likelihood that PE teachers will not leave their profession.

The main determinants of teachers' social and professional roles include a system of government, social hierarchy, system of scientific and technological advancement, the level of scientific organization of work, axiological and normative system, social value and the role of education, promotion prospects, the range of out-of-school sources of information and means of disseminating information, social status and prestige, and earnings. Social and professional roles of teachers are not constant as they undergo various changes and often evolve dynamically, e.g., as a result of the evolution of opinions regarding the essence and goals of education (Cieśliński, 2005).

Teachers' fulfillment of social and professional roles and, first and foremost, their performance of functions and tasks resulting from expectations varies. It depends both on their personalities, motives, and expectations as well as on the school community, interactions and relations with superiors and colleagues, type of school, and teachers' areas of expertise. How teachers perform their social and professional roles is largely influenced by social milieus particularly interested in their work, students' parents, and future employers as well as society in general (through its representatives who make specific demands and impose concrete obligations) (Cieśliński, 2005).

The social role of teachers has been the subject of scientific investigations for many years. The comparison of studies by Ryszard Cieśliński (2005) and Zbigniew Krawczyk (1978) revealed that the demands imposed by contemporary society on teachers (including PE specialists) did not differ even though both investigations were carried out at different times and in different social and political systems. They were still very high, internally volatile, and diversified. Currently, there is a growing discrepancy between the expected and actual social role of teachers. To a large extent it stems from the fact that the division between professional and social activities of this group is unclear (Cieśliński, 2005; Krawczyk, 1978). Therefore, in the case of teachers (PE teachers in particular), the role is not explicitly defined and it can create conflicts. This is one of the reasons why teachers find it difficult to meet the diverse and increasing demands of individuals and social groups they deal with on social grounds. It often leads to the conflict of roles and to a number of problems that force PE teachers to leave their profession.

Effective fulfillment of social roles by PE teachers is conditioned by their ability to face many difficult contemporary challenges. These include intensive changes in social awareness that result from the development of mass media, the influence of marketing mechanisms, spin techniques, and popular culture. Other challenges are as follows: common occurrence of individualistic behavior and materialism accompanied by the weakening of social bonds, an increase in the levels of aggression, various addictions (to psychoactive substances as well as to activities and patterns of behavior), changes in attitude, and in 
expectations concerning the system of education. All these aspects are potentially stress inducing and mentally tiring, and may negatively affect teachers' performance of their professional duties (Tucholska, 2009; Litzke \& Schuh, 2005). Physical and mental fatigue may lead to teachers' total exhaustion and, ultimately, to their leaving the profession.

However, such a decision is not made "on the spur of the moment". It is an ongoing process that often starts at the beginning of their career (the so-called "honeymoon") when they are still full of energy, enthusiasm, and optimism. It is associated with their initial fascination with work when they can only see the advantages of the job. However, after the "honeymoon" period there comes the time of "awakening", when teachers start to perceive their work as it really is, i.e., with all its difficulties and problems. Yet they still try to do their best to achieve their teaching goals. The next phase of the process of burning out is called "roughness". At this stage, teachers have to put in more and more work and effort in order to perform their professional tasks at least to a satisfactory degree. Nonetheless, their interpersonal relations with both students and colleagues are not proper as misunderstandings and conflicts occur. As a consequence, they reach the stage of "full-blown burnout". They become physically, mentally, and emotionally exhausted. They suffer from depression and nervous breakdowns; a feeling of failure, emptiness, and loneliness occurs. Therefore, they feel they need to escape from professional problems and give up their job. This is the moment when they often take the decision to leave their profession. However, if they manage to pull through and overcome this crisis, they get to the stage of "revival". This is a time of making up for losses and correcting pedagogical mistakes as well as mental recovery and healing emotional wounds resulting from going through earlier phases of the burnout process (Kazimierowicz, 2012). First, this means that teachers taking a decision to leave their profession do it at the last but one stage of the burnout process, when it is still possible to go through the last phase that leads to overcoming the crisis and returning to homeostasis; second, they are not fully burned out yet but extremely frustrated with the conditions and effects of their work.

The most common indirect reasons why PE teachers leave their profession include the quantity and quality of duties and tasks, excessive bureaucracy, school directors' expectations concerning teachers' commitment, availability and effectiveness of task performance, excessive control and limited independence, and the lack of clearly defined goals and no possibility to identify with them (Sparkes \& Templin, 1992). Furthermore, they include mismanagement, unfriendly atmosphere among staff, insufficient support from their colleagues, no participation in making significant decisions, limitations regarding the fulfillment of professional roles that result in dissatisfaction with work, and a sense of too low remuneration (Solomon et al., 1993).

The literature review indicates that most works regarding PE teachers define their professional career as hardly ever fully satisfying. Simultaneously, a lot of publications point to satisfaction as the most important factor that prevents teachers from leaving their profession (Whipp et al., 2007).

\section{Conclusions}

Analysis of the research results revealed that professional burnout does occur among PE teachers, although the decision to leave the profession is usually based on other causes, the most important being financial reasons (frustration brought about by remuneration subjectively perceived as low).

Furthermore, it was observed that PE teachers of both sexes were usually hit by a serious professional crisis approximately in their fifth year of work. This was not related to the type of personality, but mainly some individual features as well as working conditions and situations that exerted influence on whether they experienced a crisis or had the tendency to burn out.

PE teachers' decision to leave the profession is affected by the accumulation of such problems as the conflict of interests between them and their supervisors, insufficient participation in making decisions related to the school, no possibilities to make full use of their knowledge and skills and the accompanying sense of 
inefficacy when taking up different activities, lower and lower status of teachers, and no respect from students and their parents.

When PE teachers experience problems at work that make them consider the decision to give up their job, they mainly rely on other PE teachers, who may provide support and prevent them from leaving the profession. In turn, arguments and conflicts among teaching staff contribute considerably to their burnout and the decision to leave the profession.

The data analysis showed that in many cases PE teachers left their profession not due to one decisive reason but because there were two or more equally important causes.

As more and more teachers leave their profession, social support is a preventive measure. This support is understood as the realization of the social solidarity rule. It is realized through help provided to an individual as a result of the bond that ties a human being to other people, social groups, and society. Giving social support is fundamental when it comes to mental health and the vitality of an individual. The possibility to get support, consolation, and help from particular people, groups, or institutions, positively influences individuals who serve professional and social roles, and enables them to maintain relations and cooperation in the social environment and to strengthen bonds with society. Making use of a real support system in case of emergency may, to a large extent, help teachers solve problems and cope with various difficulties.

A significant matter regarding the reasons why teachers (including PE teachers) leave their profession is their love of the job. A vocation and sense of mission are invaluable and indispensable when one wishes to find fulfillment in teaching. Moreover, it is essential to comprehend the objectives of activity in this profession. Apart from teaching and educating, it is necessary to shape pro-social behavior, develop a system of values, form proper attitudes to moral norms, and to be responsible for another human, i.e., students. It is also crucial to be aware of the fact that working in the teaching profession means performing a prestigious social service.

\section{REFERENCES}

Babbie, E. (2001). The Practice of Social Research. Belmont: Wadsworth/Thomson Learning.

Cieśliński, R. (2005). Socio-professional situation of physical education teachers. Warszawa: AWF.

Kazimierowicz, M. (2012). Professional burnout of teachers - fiction or reality? Nowa Szkoła, 10, 26-31.

Krawczyk, Z. (1978). Graduates of universities of physical education. Social study of the profession. Warszawa: AWF.

Litzke, S.M. \& Schuh H. (2005). Stress, Mobbing und Burn-out am Arbeitsplatz. Heidelberg: Springer-Verlag.

Louis, K.S. \& Smith B. (1990). Teacher working conditions. In P. Reyes (Ed.), Teachers and their workplace: commitment, performance and productivity (pp. 23-47). Newberry Park: Sage.

Louis, K.S. \& Smith B. (1991). Restructuring, teacher engagement and school culture: perspectives on school reform and the improvement of teacher's work. International Journal of Research, Policy and Practice, 2(1), 34-52.

Solomon, M., Worthy T. \& Carter J. (1993). The interaction of school context and the role identity of first year teachers. Journal of Teaching in Physical Education, 12, 313-328.

Sparkes, A.C. \& Templin T.J. (1992). Life histories and physical education teachers: exploring the meanings of marginality. In A.C. Sparkes (Ed.), Research in physical education and sport: exploring alternative visions (pp. 118145). London: Falmer Press.

Tucholska, S. (2009). Professional burnout in teachers. Psychological analysis of the phenomenon and its conditionings. Lublin: Wydawnictwo KUL.

Whipp, P.R., Tan G. \& Yeo P.T. (2007). Experienced physical education teachers reaching their use-by date: powerless and disrespected. Research Quarterly for Exercise and Sport, no. 78(5), 487-99. 
AUTHOR'S ADDRESS: $\quad$ Ryszard Cieśliński

Faculty of Physical Education and Sport

2 Akademicka

21-500 Biała Podlaska, Poland

e-mail: knh@awf-bp.edu.pl 